\title{
Ventilation and perfusion scans in the preoperative assessment of bronchial carcinoma
}

\author{
D. J. LIPSCOMB AND N. B. PRIDE
}

From the Department of Medicine, Royal Postgraduate Medical School, Hammersmith Hospital, London W12 OHS, UK

\begin{abstract}
Lipscomb, D. J. and Pride, N. B. (1977). Thorax, 32, 720-725. Ventilation and perfusion scans in the preoperative assessment of bronchial carcinoma. Ventilation (krypton $-81 \mathrm{~m}$ ) and perfusion (technetium $-99 \mathrm{~m}$ ) lung scans were obtained in a consecutive series of 21 patients shortly before thoracotomy for proven or suspected carcinoma of the bronchus. In most patients ventilation and perfusion were impaired equally and the scan abnormality corresponded to the bronchoscopic and radiological findings. Unexpectedly large defects in the perfusion scan were seen in three patients, all of whom had extensive neoplastic involvement of the mediastinum at thoracotomy, but 11 other patients had mediastinal involvement which was not suspected from the scan. Ventilation scanning was useful in the prediction of postoperative ventilatory capacity in two patients who underwent pneumonectomy. We conclude that ventilation and perfusion scans are not sensitive indicators of neoplastic involvement of the mediastinum but they are valuable for the prediction of postoperative lung function.
\end{abstract}

Although some tests of regional lung function have been available for many years, until recently they have not been widely available and have not been used routinely in the preoperative assessment of patients with bronchial carcinoma. After the introduction of lung perfusion scans using technetium-labelled albumin, several studies have shown that abnormalities of perfusion often are greater than predicted from the chest radiograph and bronchoscopy (Wagner et al., 1965; Garnett et al., 1968; Vassallo et al., 1968; Maynard et al., 1969), and it has been suggested that a reduction of perfusion in the affected lung to less than onethird of the total indicates inoperability (SeckerWalker and Provan, 1969; Secker-Walker et al., 1971, 1974). Unfortunately, hitherto there has been no comparable method of assessing regional ventilation; bronchospirometry is available in only a few centres and radioactive xenon has theoretical and practical disadvantages (Matthews and Dollery, 1965). The advent of a new and simple technique for measuring regional ventilation during tidal breathing using the inert gas krypton $-81 \mathrm{~m}$ (Fazio and Jones, 1975) has overcome many of these problems. In the present study we have obtained preoperative ventilation and perfusion scans in 21 consecutive patients submitted to surgery for a suspected or proven bronchial neoplasm with the aim of assessing their value in predicting mediastinal involvement and postoperative ventilatory capacity.

\section{Patients and methods}

Patients with suspected bronchial carcinoma were investigated by standard methods including chest radiography, sputum cytology, bronchoscopy, measurement of lung function, blood gases, and 욱 (in two patients only) mediastinoscopy. The de- $\rightarrow$ cision to operate was made on these findings by the clinician in charge. In those patients con- $N$ sidered suitable for surgery, ventilation and per- $\%$ fusion scans were performed a few days (usually 0 48 hours) before surgery. Perfusion scans were $\underset{\omega}{ }$ obtained in the usual way (Taplin et al., 1964) by injecting $1 \mathrm{mCi}$ of ${ }^{9{ }^{\mathrm{m}}} \mathrm{Tc}$-labelled human serumo albumin macroaggregates or microspheres intravenously. The patient was seated in front of $a \stackrel{?}{?}$ gamma camera (Toshiba GCA-202 large field). A 꿈 conventional image was stored on Polaroid or 35 용 $\mathrm{mm}$ film; digital data were recorded in some cases using a mini-computer (Data General Corporation $\stackrel{\mathbb{Q}}{\varrho}$ Nova 1220). Ventilation scans were recorded in the manner described by Fazio and Jones (1975) 
with the patient breathing room air through a disposable face-mask to which a constant supply of ${ }^{\mathrm{s} 1 \mathrm{~m}} \mathrm{Kr}$ was added. Anterior and posterior views were recorded and the counting field for the whole thorax was divided vertically into two halves; by summing the anterior and posterior views, the contribution of each lung as a percentage of the total ventilation or perfusion was calculated.

Lung function was measured on all subjects preoperatively and on some patients postoperatively. Spirometry was recorded on a dry spirometer (McDermott et al., 1968). Lung volumes were measured in the whole body plethysmograph (DuBois et al., 1956). Tranfer factor for carbon monoxide was measured by the single breath method (Ogilvie et al., 1957).

\section{Results}

\section{PREOPERATIVE ASSESSMENT}

The preoperative radiological, bronchoscopic, and scanning findings are summarised in Table 1. The patients were divided into two groups on the basis of the radiological findings. The nine patients in group A all had a solitary small opacity well clear of the mediastinum; in most cases bronchoscopy (including cytology of the suckings) was normal and thoracotomy was undertaken diagnostically. The scans were either normal or showed only a small defect of ventilation and perfusion of equal proportions which corresponded to the opacity on the chest radiograph. The 12 patients in group $B$ had larger and more centrally placed tumours which were usually bronchoscopically visible and of ten caused collapse or consolidation; although the mediastinum was not known to be involved, it was to be expected that this group would have more extensive disease. The scan abnormalities were greater than in group A, but defects corresponded to the areas of bronchoscopic and radiographic abnormality in all but three patients (11, $17,18)$. Significant abnormalities were not seen in the contralateral lung. The figures for split-field counting tend to obscure regional changes, which were more obvious to the naked eye, possibly owing to compensatory changes in the remaining lung; the results do, however, serve to illustrate that major discrepancies between changes in ventilation and perfusion were unusual. Two patients $(11,18)$ had a mild, generalised reduction in perfusion throughout the affected hemithorax. In patient 17 there was a tumour in the main bronchus; the upper lobe was completely collapsed and the lower lobe bronchus partially obstructed. As

Table 1 Preoperative assessment

\begin{tabular}{|c|c|c|c|c|c|c|c|c|}
\hline Group & Patient & Age & $\operatorname{Sex}$ & Chest radiograph* & Bronchoscopy $\dagger$ & Scan & $\dot{V}(\%)$ & $\dot{Q}(\%)$ \\
\hline \multirow[t]{9}{*}{$\mathbf{A}$} & 1 & 40 & $\mathbf{M}$ & $1.5 \mathrm{~cm}$ peripheral mass $\mathrm{LUL}$ & Normal & Normal & 47 & 47 \\
\hline & 2 & 52 & $\mathbf{M}$ & $1 \mathrm{~cm}$ peripheral mass $\mathrm{LUL}$ & Normal & Normal & 46 & 46 \\
\hline & 3 & 68 & $\mathbf{F}$ & $3 \mathrm{~cm}$ peripheral mass lingula & Positive + & Small defect $\dot{\mathbf{V}}=\mathbf{Q}$ & 45 & 45 \\
\hline & 4 & 60 & $\mathbf{F}$ & $2 \mathrm{~cm}$ peripheral mass $L U L$ & Normal & Normal & 48 & 49 \\
\hline & 5 & 61 & $\mathbf{M}$ & $3 \mathrm{~cm}$ peripheral mass lingula & Normal & Small defect $\dot{\mathbf{V}}=\mathbf{Q}$ & 44 & 46 \\
\hline & 6 & 56 & $\mathbf{F}$ & $3.5 \mathrm{~cm}$ peripheral mass LLL & Suggestive & Small defect $\dot{\mathbf{V}}=\dot{\mathbf{Q}}$ & 44 & 44 \\
\hline & 7 & 53 & $\mathbf{M}$ & $2 \mathrm{~cm}$ peripheral mass RUL & Normal & Small defect $\dot{\mathbf{V}}=\grave{Q}$ & 52 & 51 \\
\hline & 8 & 71 & $\mathbf{M}$ & $2.5 \mathrm{~cm}$ peripheral mass RLL & Normal & Small defect $Q>\dot{V}$ & 52 & 47 \\
\hline & 9 & 56 & $\mathbf{F}$ & $1.5 \mathrm{~cm}$ peripheral mass RUL & Normal & Normal & 57 & 55 \\
\hline \multirow[t]{11}{*}{ B } & 10 & 61 & $\mathbf{M}$ & Collapsed RML and RLL & Positive ++ & Reduced $\dot{\mathbf{V}}>\mathbf{Q}$ at $\mathbf{R}$ base & 39 & 43 \\
\hline & 11 & 61 & $\mathbf{F}$ & Collapsed RML and RLL & Positive ++ & $\begin{array}{l}\text { Absent } \dot{V} \text { and } Q R \text { base. } \\
\text { Reduced } Q \text { in remainder of } \\
\text { affected lung } \ddagger\end{array}$ & 46 & 36 \\
\hline & 12 & 71 & $\mathbf{M}$ & Consolidation RML and RLL & Positive ++ & Reduced $\dot{V}>\mathbf{Q}$ at $\mathbf{R}$ base & 34 & 38 \\
\hline & 13 & 58 & $\mathbf{M}$ & $\begin{array}{l}\text { Collapsed RML and RLL. } \\
\text { Hilar mass }\end{array}$ & Positive ++ & Reduced $\dot{V}>\mathbf{Q}$ RLL & 45 & 49 \\
\hline & 14 & 55 & $\mathbf{M}$ & $2 \mathrm{~cm} \times 6 \mathrm{~cm}$ mass at left hilum & Normal & Minimal reduction $\dot{\mathbf{V}}=\mathbf{Q}$ RUL & 44 & 43 \\
\hline & 15 & 56 & $\mathbf{M}$ & $6 \mathrm{~cm}$ mass LUL & Suggestive & Reduced $\mathbf{Q}>\mathbf{V}$ LUL & 41 & 38 \\
\hline & 16 & 46 & $\mathbf{M}$ & Collapsed LLL & Positive $++t$ & Reduced $\dot{V}=\dot{Q} \mathbf{L L}$ & 39 & 33 \\
\hline & 17 & 55 & $\mathbf{M}$ & $\begin{array}{l}\text { Collapsed LUL. Hyperinfiated } \\
\text { LLL }\end{array}$ & Positive $+t+$ & Absent $\dot{V}$ and $Q \mathbf{L}$ lung & 0 & 0 \\
\hline & 18 & 65 & $\mathrm{~F}$ & $3 \mathrm{~cm}$ left hilar mass & Positive ++ & $\begin{array}{l}\text { Reduced } \dot{\mathbf{V}}=\dot{Q} \mathbf{L L L} . \text { Reduced } \\
\dot{Q} \text { in remainder of affected lung }+\end{array}$ & 41 & 29 \\
\hline & 19 & 63 & $\mathbf{M}$ & $7 \mathrm{~cm}$ mass $\mathrm{LUL}$ & Normal & $\begin{array}{l}\text { Slight reduction of } Q \text { LUL. } \\
\text { Normal } \dot{V}\end{array}$ & 43 & 44 \\
\hline & $\begin{array}{l}20 \\
21\end{array}$ & $\begin{array}{l}55 \\
45\end{array}$ & $\begin{array}{l}\mathbf{M} \\
\mathbf{M}\end{array}$ & $\begin{array}{l}\text { Normal } \\
8 \mathrm{~cm} \text { mass LLL }\end{array}$ & $\begin{array}{l}\text { Positive }+++ \\
\text { Positive }++\end{array}$ & $\begin{array}{l}\text { Reduced } \dot{V}=\dot{L} L \mathbf{L} \\
\text { Defect of } \dot{V}=\dot{L} L \mathbf{L}\end{array}$ & $\begin{array}{l}38 \\
40\end{array}$ & $\begin{array}{l}36 \\
39\end{array}$ \\
\hline
\end{tabular}

*LUL, LLL = left upper and lower lobes; RUL, RML, RLL = right upper, middle, and lower lobes.

†Suggestive $=$ distortion of bronchus by extrinsic mass; Positive = tumour seen and biopsy positive.

Tumour site: + segmental bronchus; ++1 st order bronchus; +++ main bronchus.

$\ddagger$ Scan abnormality greater than expected from radiological and bronchoscopic findings.

$\dot{\mathbf{V}}=\%$ of total ventilation going to affected lung; $\mathbf{Q}=\%$ of total perfusion going to affected lung. 
expected, there was no activity on the ventilation scan but, in addition, there was no significant perfusion in the affected hemithorax.

\section{OPERATIVE FINDINGS (Table 2)}

In most patients of group A a localised tumour with no intrathoracic or mediastinal spread was found; two $(1,2)$ had benign tumours and in each case the distribution of scan counts was normal. In two patients $(5,6)$, despite the 'reassuring' scan, extensive mediastinal disease was found. All patients in group B had neoplastic involvement of the mediastinum to a varying degree; even when examined retrospectively, in most patients the scan abnormalities did not seem to reflect this. In the patient (17) in whom there was no significant perfusion of the affected lung the main blood vessels were patent macroscopically and microscopically.

\section{LUNG FUNCTION}

It was possible to study lung function three to six months postoperatively in nine patients (Table 3); the remaining patients were not available either because of advanced carcinoma causing ill-health or because they were being followed up at other hospitals. Two patients underwent segmental resection; spirometry and total lung capacity (TLC) were unchanged in one and in the other TLC was reduced by 0.7 litre. The five patients who underwent lobectomy all had a functioning lobe removed yet in three lung volumes did not alter;
TLC was reduced by about 0.5 litre in the other two patients. In the two patients studied after pneumonectomy postoperative predictions of lung function have been made from the preoperative $\varnothing$ ventilation scan, split-field counting having shown $\nRightarrow$ the contribution of the lung to be removed. In $\vec{\circ}$ both patients this prediction seems reasonably accurate. Patient 17 had a preoperative 'functional $\vec{\omega}$ pneumonectomy' with no scan activity on the left although the lower lobe remained inflated on the chest radiograph. Spirometry and alveolar volume, $N$ as measured by single breath helium dilution (for $\sigma$ the measurement of transfer factor), were therefore unchanged. There was a $1 \cdot 1$ litre fall in TLC O and in residual volume measured in the body $\triangle$ plethysmograph, presumably reflecting the removal of gas trapped in the left lower lobe.

\section{Discussion}

Earlier reports (Wagner et al., 1965; Garnett et al., $\vec{\varphi}$ 1968; Vassallo et al., 1968; Maynard et al., 1969) have shown that unexpectedly large perfusion scan abnormalities may be found in patients with carcinoma of the bronchus. We had hoped that combined ventilation and perfusion scans might prove to be a useful method for screening patients preoperatively for mediastinal and hilar involvement. Unfortunately, in the present series 14 of 21 patients were found to have malignant involvement of the mediastinum or hilar glands at opera-

Table 2 Operative findings

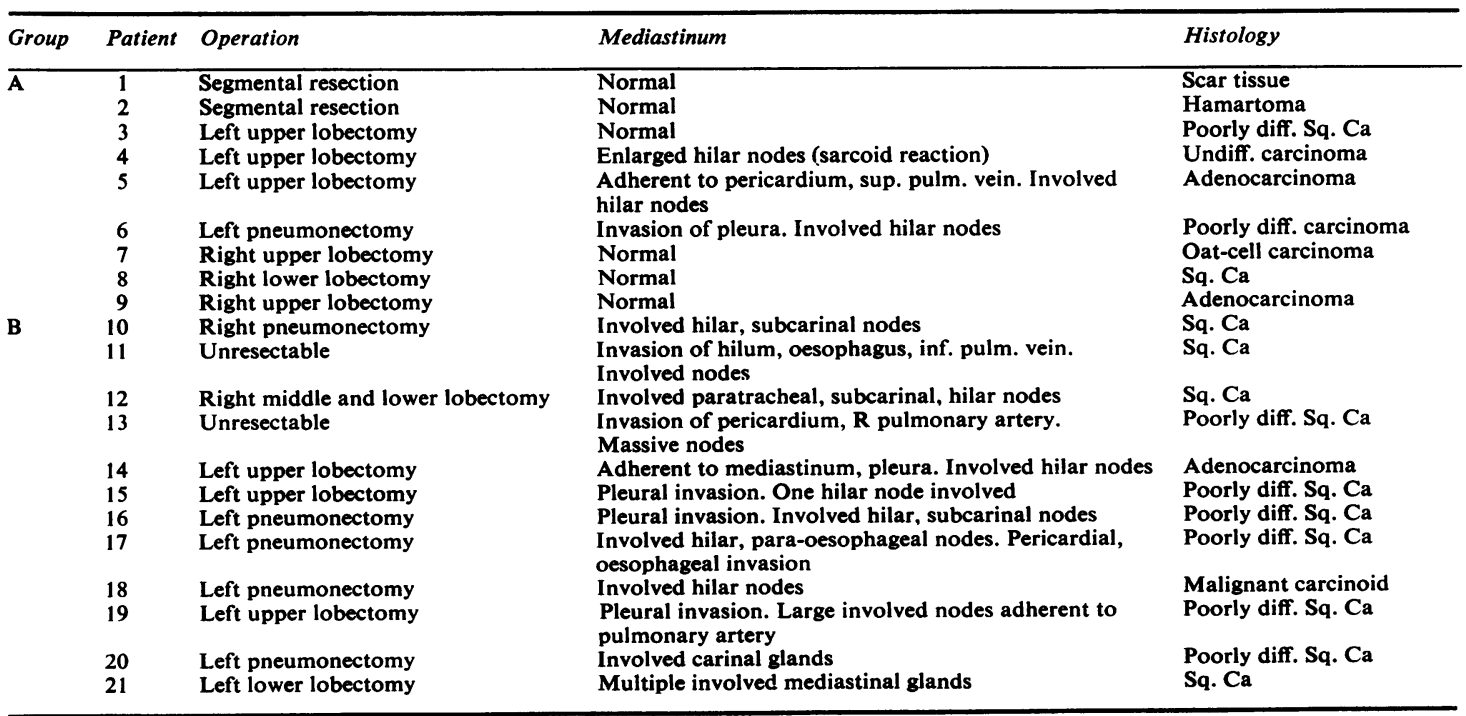

Sq. $\mathbf{C a}=$ squamous-cell carcinoma $;$ diff. $=$ differentiated. 
Table 3 Pre- and postoperative lung function

\begin{tabular}{|c|c|c|c|c|c|c|c|c|}
\hline Patient & Operation & & $\begin{array}{l}F E V_{1} \\
(l)\end{array}$ & $\begin{array}{l}V C \\
(l)\end{array}$ & $\begin{array}{l}R V \\
(l)\end{array}$ & $\begin{array}{l}T L C \\
(l)\end{array}$ & $\begin{array}{l}V A \\
(l)\end{array}$ & $\begin{array}{l}K C O \\
\left(\text { mmol min }^{-1}\right. \\
\left.\mathrm{KPa}^{-1} l^{-1}\right)\end{array}$ \\
\hline \multirow[t]{2}{*}{1} & Segmental resection & Preop & $3 \cdot 1$ & $5 \cdot 7$ & $3 \cdot 4$ & $9 \cdot 1$ & & \\
\hline & & Postop & $3 \cdot 2$ & 5.9 & $3 \cdot 3$ & $9 \cdot 1$ & & \\
\hline \multirow[t]{2}{*}{2} & Segmental resection & Preop & $3 \cdot 1$ & 3.9 & $2 \cdot 0$ & 5.9 & & \\
\hline & & Postop* & $2 \cdot 6$ & $3 \cdot 4$ & $1 \cdot 8$ & $5 \cdot 2$ & & \\
\hline \multirow[t]{2}{*}{3} & Left upper lobectomy & Preop & $1 \cdot 1$ & $2 \cdot 3$ & - & - & & \\
\hline & & Postop* & $1 \cdot 1$ & $2 \cdot 1$ & - & - & & \\
\hline \multirow[t]{2}{*}{5} & Left upper lobectomy & Preop & $2 \cdot 1$ & $3 \cdot 5$ & $2 \cdot 3$ & $5 \cdot 8$ & & \\
\hline & & Postop* & 1.9 & $3 \cdot 2$ & $2 \cdot 7$ & $5 \cdot 9$ & & \\
\hline \multirow[t]{2}{*}{7} & Right upper lobectomy & Preop & $2 \cdot 5$ & $3 \cdot 5$ & $3 \cdot 5$ & $7 \cdot 0$ & & \\
\hline & & Postop & $2 \cdot 3$ & $3 \cdot 6$ & $3 \cdot 3$ & 6.9 & & \\
\hline \multirow[t]{2}{*}{8} & Right lower lobectomy & Preop & $2 \cdot 4$ & $3 \cdot 7$ & $3 \cdot 0$ & $6 \cdot 7$ & & \\
\hline & & Postop & $2 \cdot 1$ & $3 \cdot 4$ & $2 \cdot 6$ & $6 \cdot 0$ & & \\
\hline \multirow[t]{2}{*}{9} & Right upper lobectomy & Preop & $2 \cdot 5$ & $3 \cdot 3$ & $2 \cdot 0$ & $5 \cdot 3$ & & \\
\hline & & Postop* & $2 \cdot 1$ & $2 \cdot 8$ & $2 \cdot 0$ & $4 \cdot 8$ & & \\
\hline \multirow[t]{3}{*}{10} & Right pneumonectomy & Preop & $2 \cdot 4$ & $3 \cdot 2$ & $1 \cdot 8$ & $5 \cdot 0$ & $4 \cdot 3$ & $1 \cdot 0$ \\
\hline & & Postop & $1 \cdot 6$ & $2 \cdot 0$ & $1 \cdot 5$ & $3 \cdot 4$ & $2 \cdot 7$ & $1 \cdot 4$ \\
\hline & $R$ lung $\dot{V}=39 \%$; prediction from $\dot{V}$ scan & & $1 \cdot 5$ & $2 \cdot 0$ & $1 \cdot 0$ & 3.0 & $2 \cdot 6$ & - \\
\hline \multirow[t]{3}{*}{17} & Left pneumonectomy & Preop & $2 \cdot 1$ & $2 \cdot 5$ & $3 \cdot 4$ & 5.9 & $3 \cdot 8$ & $2 \cdot 0$ \\
\hline & & Postop & 1.9 & $2 \cdot 5$ & $2 \cdot 3$ & $4 \cdot 8$ & $3 \cdot 7$ & $2 \cdot 1$ \\
\hline & $L$ lung $\dot{V}=0 \%$; prediction from $\dot{V}$ scan & & $2 \cdot 1$ & $2 \cdot 5$ & - & - & $3 \cdot 8$ & - \\
\hline
\end{tabular}

All lung volumes expressed at BTPS: $F E V_{1}=$ forced expiratory volume in 1 second; $V C=$ vital capacity; $R V=$ residual volume; $T L C=$ total lung capacity; $\mathrm{VA}=$ alveolar volume (single breath dilution of helium); $\mathrm{KCO}=$ transfer factor for carbon monoxide/VA. To convert results to min $^{-1}$ $\mathrm{mmHg}^{-1}$ multiply results in table by 2.99 .

*Small pleural reaction on chest radiograph at time of postoperative study.

tion, but only in three of these patients were there scan defects which were greater than anticipated from bronchoscopic and radiological assessment. Two of the patients in group A with apparently discrete peripheral carcinomas had extensive mediastinal disease without scan defects outside the area of the peripheral opacity; the patients in group B had larger scan defects but it was not possible to relate these to the degree of mediastinal involvement. It has been suggested (Secker-Walker and Provan, 1969; Secker-Walker et al., 1971, 1974) that when perfusion of the affected lung is reduced to one-third or less of the total the tumour is likely to be unresectable; in the two patients who were unresectable in the present series, perfusion of the affected lung was $36 \%$ of the total in patient 11 and $49 \%$ in patient 13 , while resec- tion was possible in all three patients in whom perfusion of the affected lung was one-third or less of the total. These results confirm the opinion of Maynard et al. (1969) that it is not possible to predict operability with confidence from the perfusion scan. They also indicate that scanning is not a sensitive detector of mediastinal involvement. Earlier studies probably have included patients with more advanced disease who were not considered for surgery; certainly experience in this hospital confirms that scan defects are commonly greater than anticipated from the chest radiograph in patients starting treatment with radiotherapy (McKenzie, 1976). In the present small series there were no 'false-positive' scan defects; an extensive scan defect was associated with extensive mediastinal involvement at operation. 
It was possible to study pre- and postoperative spirometry and lung volume in seven patients who had limited resections (of a lobe or segment) and in two patients who had a pneumonectomy. Thoracotomy alone is known to reduce the vital capacity and maximum breathing capacity for several weeks, but by six weeks after operation recovery is usually complete (Gorlin et al., 1957). In the two patients who had segmental resections, only about $5 \%$ of functioning lung tissue was probably removed (Kristersson et al., 1973); in patient 2 , in whom there was some loss of volume, a pleural reaction developed postoperatively on the chest radiograph. The changes after lobectomy were surprisingly small, significant reduction in volumes being found in only two of the five patients despite preoperative scans which indicated well-preserved function in the lobes removed. Kristersson et al. (1973) have estimated that the right upper lobe contributes about $16 \%$ and the right lower lobe and the left upper lobe (including the lingula) each about $26 \%$ of total volume, so our results suggest some compensatory increase in the volume of the remaining lobes. Similar results have been reported previously (Kamener $e t$ al., 1958) although others have found postoperative function in adults to be only slightly less impaired than would be predicted from the number of functioning segments removed (Kristersson et al., 1973). Preoperative scanning is particularly valuable in assessing suitability for pneumonectomy where postoperative lung function depends on the extent of surviving function in the lung to be resected, which is not easy to assess by clinical, bronchoscopic, and radiological examination alone. In the two patients in the present series an accurate prediction of postoperative function was possible using the preoperative scan. The change in transfer of carbon monoxide will also depend on the degree of function remaining in the affected lung. If the cardiac output has already been diverted to the unaffected lung then no change in transfer factor per unit volume (KCO) would be expected (patient 17); if the removed lung had been receiving significant perfusion then the flow and blood volume in the remaining lung will increase postoperatively, resulting in a rise in $\mathrm{KcO}$ (patient 10).

Accurate predictions of postoperative ventilatory capacity were attempted only in patients undergoing pneumonectomy because of the way in which the scans were analysed; if a lobectomy is planned, a quadrantic analysis of the counting field would be more helpful. This type of analysis does, however, involve a computer; even without sophisticated data collection systems the ventila- tion scan should allow an informed estimate of postoperative ventilatory function that will be useful clinically. Although our experience of this is small, others have confirmed the predictive ability of ventilation scans (Kristersson et al., के 1972), and the simplicity and theoretical advan- $\vec{\circ}$ tages of krypton make it preferable to xenon.

If ventilation scanning facilities are not avail- $\vec{\omega}$ able, postoperative forced expiratory volume can $\stackrel{\circ}{\rightleftharpoons}$ be predicted with reasonable accuracy (although $\vec{x}$ there is a tendency to underestimate postoperative values) from the technetium perfusion scan alone, $\sigma$ using split-field counting (Olsen et al., 1974). Al- N though a somewhat better prediction of postoperative forced expiratory volume can be obtained from preoperative ventilation scans (Kristersson $\vec{\nabla}$ et al., 1973), the present study confirms that major discrepancies between ventilation and perfusion $\Phi$ are unusual (Table 1) so that errors arising from using perfusion data should be uncommon.

We conclude that ventilation and perfusion $\overrightarrow{0}$ scanning is not a sensitive indicator of mediastinal $\exists$ involvement in candidates for surgery for bronchial carcinoma, but that when an unexpectedly large defect is present this is likely to indicate extensive mediastinal disease. The use of ventilation scanning in conjuction with overall $\stackrel{\circ}{\odot}$ lung function tests should allow a much more $\varrho$ accurate assessment to be made of postoperative $\overrightarrow{\bar{O}}$ ventilatory function and should be particularly valuable in patients who are likely to require pneumonectomy or who have generalised airway or lung disease.

We are grateful to the Radiology Department of $\stackrel{2}{x}$ Hammersmith Hospital for performing the scans $\frac{0}{3}$ and to T. Pratt, in particular, for expert technical assistance; Dr. P. Lavender reported on the scans. We thank the consultants at Hammersmith Hospital and Harefield Hospital for referring 음 patients under their care. We particularly acknowledge the assistance of R. Sapsford, FRCS, and D. Cooper, FRCS, who performed most of the opera- $N$ tions. Miss Vivienne DuBurguet typed the manuscript.

\section{References}

DuBois, A. B., Botelho, S. Y., Bedell, G. N., Marshall, R., and Comroe, J. H. Jr. (1956). A rapid plethysmographic method for measuring thoracic gas volume: ? a comparison with a nitrogen washout method for $\underline{T}$ measuring functional residual capacity in normalo subjects. Journal of Clinical Investigation, 35, 322326.

Fazio, F., and Jones, T. (1975). Assessment of regional $\varrho$ ventilation by continuous inhalation of radioactive? Krypton-81m. British Medical Journal, 3, 673-676. 
Garnett, E. S., Goddard, B. A., Fraser, H. S., and Macleod, W. M. (1968). Lung perfusion patterns in carcinoma of bronchus. British Medical Journal, 2, 209-210.

Gorlin, R., Knowles, J. H., and Storey, C. F. (1957). Effects of thoracotomy on pulmonary function. Journal of Thoracic Surgery, 34, 242-249.

Kamener, R., Becklake, M. R., Goldman, H., and McGregor, M. (1958). Respiratory function following segmental resection of the lung for bronchiectasis. American Review of Tuberculosis and Pulmonary Diseases, 77, 209-220.

Kristersson, S., Arborelius, M., Jr., Jungquist, G., Lilja, B. and Svanberg, L. (1973). Prediction of ventilatory function after lobectomy. Scandinavian Journal of Respiratory Disease, 54, 315-325.

Kristersson, S., Lindell, S. E., and Svanberg, L. (1972). Prediction of pulmonary function loss due to pneumonectomy using ${ }^{133} \mathrm{Xe}$-radiospirometry. Chest, ${ }^{62}$, 694-698.

McDermott, M., McDermott, T. J., and Collins, M. M. (1968). A portable bellows spirometer and timing unit for the measurement of respiratory function. Medical and Biological Engineering, 6, 291-302.

McKenzie, C. G. (1976). The functional assessment of lung cancer patients before and after radiotherapy. British Journal of Diseases of the Chest, 70, 286-288.

Matthews, C. M. E., and Dollery, C. T. (1965). Interpretation of ${ }^{133} \mathrm{Xe}$ lung wash-in and wash-out curves using an analogue computer. Clinical Science, 28, 573-590.

Maynard, C. D., Miller, R. P., Heaphy, L. J., Jr., and Whitley, J. E. (1969). Pulmonary scanning in bronchogenic carcinoma. Radiology, 92, 903-907.

Ogilvie, C. M., Forster, R. E., Blakemore, W. S., and Morton, J. W. (1957). A standardized breath holding technique for the clinical measurement of the diffusing capacity of the lung for carbon monoxide. Journal of Clinical Investigation, 36, 1-17.

Olsen, G. N., Block, A. J., and Tobias, J. A. (1974). Prediction of post-pneumonectomy pulmonary function using quantitative macroaggregate lung scanning. Chest, 66, 13-16.

Secker-Walker, R. H., Alderson, P. O., Wilhelm, J., Hill, R. L., Markham, J., and Kinzie, J. (1974). Ventilation-perfusion scanning in carcinoma of the bronchus. Chest, 65, 660-663.

Secker-Walker, R. H., and Provan, J. L. (1969). Scintillation scanning of lungs in preoperative assessment of carcinoma of bronchus. British Medical Journal, 3, 327-330.

Secker-Walker, R. H., Provan, J. L., Jackson, J. A., and Goodwin, J. (1971). Lung scanning in carcinoma of the bronchus. Thorax, 26, 23-32.

Taplin, G. V., Johnson, D. E., Dore, E. K., and Kaplan, H. S. (1964). Suspensions of radioalbumin aggregates for photoscanning the liver, spleen, lung and other organs. Journal of Nuclear Medicine, 5, 259-275.

Vassallo, C. L., Gee, J. B. L., Wholey, M. H., and Vester, J. W. (1968). Lung scanning in hilar bronchogenic carcinoma. American Review of Respiratory Disease, 97, 851-858.

Wagner, H. N., Jr., Lopez-Majano, V., Tow, D. E., and Langan, J. K. (1965). Radioisotope scanning of lungs in early diagnosis of bronchogenic carcinoma. Lancet, 1, 344-347.

Requests for reprints to: Dr. N. B. Pride, Department of Medicine, Hammersmith Hospital, London W12 0HS, UK. 